\title{
O papel do treinamento de força regular versus a periodização ondulatória sobre a composição corporal e teste de marcha em idosos.
}

\begin{abstract}
Leonardo L. Lazarini (IC), Hélio J. Coelho Júnior (PG) e Marco C. Uchida (PQ).
Resumo

Esse projeto estudou a comparação da influência do treinamento de força e do treinamento ondulatório periodizado na composição corporal e do teste funcional de marcha em idosos durante 14 semanas. Selecionamos 28 mulheres acima de 65 anos inativas fisicamente e divididas aleatoriamente em 2 grupos: I) treinamento de força ondulatório ( $n=14$ cujo programa consiste em 2 sessões de treino na semana, sendo uma de potência muscular e outra de força muscular); II) treinamento de força regular $(n=14)$. Com coleta de dados pré, na $4^{\underline{a}}$ e na 14a semana, para avaliar os resultados dos diferentes tipos de treinamento. Resultados: nenhum protocolo causou alterações significativas em ambos os testes.
\end{abstract}

Palavras Chave: Envelhecimento, exercício físico, potência.

\section{Introdução}

Segundo a ONU, nos próximos 43 anos a população com mais de 60 anos de idade triplicará1.

Exercícios físicos são fundamentais na manutenção da força muscular, garantindo assim o desempenho nas atividades de vida diária (AVD).

Objetivo: verificar a influência de dois protocolos de treinamento de força (regular e ondulatório), na composição corporal e no desempenho no teste de marcha em idosas.

\section{Resultados e Discussão}

O treinamento de força muscular foi composto de 9 exercícios para os principais grupamentos musculares, com 3 séries de 8 a 10 repetições com pesos livres e máquinas ${ }^{2}$ (7-8 na escala de Borg CR-10 adaptada (Foster et. al., 2001)). O treinamento de potência muscular foi realizado com utilização de faixa elástica da marca TheraBand, para os mesmos grupamentos musculares (5-6 na mesma escala) e ação concêntrica mais rápida possível. Com 3 séries de 4 a 6 repetições. Análise estatística: análise de variância ANOVA one-way para medidas repetidas com o teste de Bonferroni como Post Hoc.

Tabela 1. Aspectos morfológicos entre grupos

\begin{tabular}{|c|c|c|c|c|c|c|}
\hline & \multicolumn{3}{|c|}{$\operatorname{TR}(n=13)$} & \multicolumn{3}{|c|}{ TO $(n=13)$} \\
\hline & Pré & $\begin{array}{c}4^{\mathrm{a}} \\
\text { (sem) }\end{array}$ & $\begin{array}{c}14^{\mathrm{a}} \\
\text { (sem) }\end{array}$ & Pré & $\begin{array}{c}4^{\mathrm{a}} \\
(\mathrm{sem})\end{array}$ & $\begin{array}{c}14^{\mathrm{a}} \\
\text { (sem) }\end{array}$ \\
\hline Peso (kg) & $\begin{array}{c}69,7 \\
\pm \\
12,2\end{array}$ & $\begin{array}{c}70,0 \\
\pm \\
12,6\end{array}$ & $\begin{array}{r}67,2 \\
\pm 9,3\end{array}$ & $\begin{array}{c}68,2 \pm \\
12,2\end{array}$ & $\begin{array}{c}68,8 \pm \\
12,7\end{array}$ & $\begin{array}{c}69,4 \pm \\
12,3\end{array}$ \\
\hline IMC $\left(\mathrm{kg} / \mathrm{m}^{2}\right)$ & $\begin{array}{r}28,7 \\
\pm 4,5\end{array}$ & $\begin{array}{c}23,6 \\
\pm \\
12,7\end{array}$ & $\begin{array}{r}27,5 \\
\pm 3,7\end{array}$ & $\begin{array}{c}27,9 \pm \\
6,3\end{array}$ & $\begin{array}{c}28,0 \pm \\
6,4\end{array}$ & $\begin{array}{r}28,3 \pm \\
6,0\end{array}$ \\
\hline Massa muscular $(\mathrm{kg})$ & $\begin{array}{r}37,8 \\
\pm 3,1 \\
\end{array}$ & $\begin{array}{r}37,5 \\
\pm 3,4 \\
\end{array}$ & $\begin{array}{r}38,7 \\
\pm 4,2 \\
\end{array}$ & $\begin{array}{c}37,4 \pm \\
4,5\end{array}$ & $\begin{array}{c}37,7 \pm \\
4,7\end{array}$ & $\begin{array}{c}36,8 \pm \\
6,7\end{array}$ \\
\hline
\end{tabular}

Figura 1. Tempo da marcha em 10 metros.

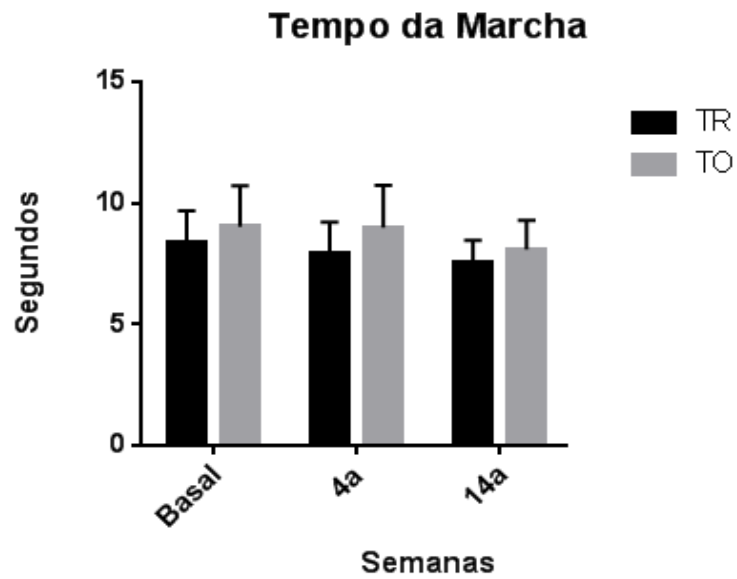

Resultados e discussão: Não houveram alterações no tempo da marcha e composição corporal, provavelmente em função de serem mulheres saudáveis, robustas. Além do TR (apesar de não estatístico) ter tido ligeiro aumento na massa muscular.

\section{Conclusões}

Ambos os treinos tiveram a capacidade de manter constante a composição corporal e o tempo da marcha, portanto sem alterações nestas.

\section{Agradecimentos}

PIBIC, CNPq, GEPEFAN, FEF - Unicamp

Félix J. S. Economia da Longevidade: uma revisão da bibliografia brasileira sobre o envelhecimento populacional. PUC - SP. s. d. ${ }^{2}$ AMERICAN COLLEGE OF SPORTS MEDICINE et al. American Collegeof Sports Medicine position stand. Exerciseandphysicalactivity for olderadults. Medicine andscience in sportsandexercise, v. 41, n. 7, p. 1510- 1530.2009 . 